\title{
An Evaluation of Correction of Idiopathic Kyphoscoliosis by Axial Translation Technique with Pedicle Screw and Rod
}

\author{
Islam $\mathrm{MA}^{1 *}$, Goni FM², Parvez $\mathrm{Q}^{2}$ \\ ${ }^{1}$ Department of Orthopaedic Surgery, Bangbandhu Sheikh Mujib Medical University, Dhaka, Bangladesh \\ ${ }^{2}$ Bangbandhu Sheikh Mujib Medical University, Dhaka, Bangladesh
}

\begin{abstract}
As sufficient study not available in this subcontinent about correction of idiopathic kyphoscoliosis by axial translation technique, a group of patients of Adolescent Idiopathic Scoliosis (AIS) was selected to evaluate the outcome of rod rotation technique. The curve correction with more screw on the concave site was assessed, patient satisfaction and correction of cobb angle. Post operative radiological and functional outcome were assessed. Twenty consecutive patients ( 8 males, 12 females) with an age range from 10 to 24 years. Post operatively all were followed-up for 18 months. All patients were under went pedicle screw instrumentation through posterior approach. More screw inserted in the concave side. X-ray evaluation done by pre-operative and 1, 3, 6,12 and 18 months after surgery. Scoliosis Research Society (SRS) questionnaire was done for clinical evaluation. Radiological evaluation done by preoperative cobb angle was significantly reduced in postoperative period. The mean postoperative SRS scores were improved from 3.38 to 4.13 . These results were statistically significant and so it may be concluded that the axial translation technique with more screw in the concave side is ideal technique with good postoperative outcome both clinically and radiologically.
\end{abstract}

Keywords: Adolescent idiopathic scoliosis, Axial translation technique, Top opening pedicle screw

\section{Introduction}

Surgical treatment of Adolescent Idiopathic Scoliosis (AIS) has been revolutionized with introduction of various strategies which include: distraction as developed by Harrington, which was followed by the development of segmental fixation which allowed segmental compression/ distraction and latter spine de rotation and translation. ${ }^{1-4}$ Each one of this technique have its own advantages and disadvantages. According to recent studies, the restoration of the sagittal balance i.e., normal thoracic kyphosis and lumbar lordosis are critical in the overall lo0ng term benefits from these surgeries. It is associated with lower risk of chronic low back pain, disability and final functional outcome with significant development of degenerative disc disease in patients with flat back or thoracic hypokyphosis. ${ }^{5}$ Wires, hooks and screws and used as spine anchors for the deformity correction with recent move toward all screws construct which shows better restoration of sagittal balance, more deformity correction and reduction of the rib hump through de rotation, avoiding the need for thoracotomy and thoracoplasty, alleviating the need for anterior release in large and stiff curves, all of which at the expense of higher cost and risk of neurological injury. ${ }^{6-8}$ Two techniques mainly used recently either using a top or side loading spinal instrumentation systems with the former using de rotation technique mainly while the later uses translation mainly. ${ }^{9-11}$ In most cases, the use of either a top or side loading spine instrumentation system is related mainly to the surgeon's preference, main method used for deformity correction. Cotrel-Dubousset (CD) introduced new system in last decade which achieved adequate reduction in frontal, sagittal and transverse planes. ${ }^{12}$ Experience with Cotrel and Dubousset (CD) system showed that spine could become unbalanced above and below the construct. This disadvantage was overcome by new design universal spine system (USS), in which frame was created by rods fixed in the cranial and caudal ends of the construct. ${ }^{13}$ Anchor points placed in intervening segments are translated into the frame - the axial translation technique. Active derotation in each of the segments can also be applied through this system. This instrumentation also allows restoration of the thoracic kyphosis and realignment of thoracic torsion by lifting the concavity out of the chest and reducing the convex rib deformity. Axial translation technique being is one of the good 
option for deformity correction.10 This study was aimed to evaluate the result of deformity correction by this technique.

\section{Materials and Methods}

This prospective study was conducted among twenty consecutive patients treated in Bangbandhu Sheikh Mujib Medical University (BSMMU), Dhaka and other private hospital in Dhaka who underwent posterior correction of scoliosis with all pedicle screw construct by the axial translation technique during January 2014 to June 2018. The indication for surgery in these cases was Cobb's angle of $40^{\circ}$ or more but less than $90^{\circ}$ with significant chest wall deformity. Preoperative Xray, MRI, CT scan were done. All the patients were available for follow-up. The follow-up period of 18 months. There were eight males and twelve females. The average age was 14.24 years. Scoliogram was done in all patients. X-ray of whole spine taken both $\mathrm{A} / \mathrm{P} \&$ lateral view after $3^{\text {rd }}$ postoperative day and $6,12,18^{\text {th }}$ month follow-up. Cobb's angle measured, C7 plumb line, apical vertebral translation (standing radiographs) were noted in all these patients. Upper and lower fusion levels were recorded. Postoperative $\mathrm{x}$-ray was done to see body fusion. Patients were positioned prone under general anaesthesia. The desired level was exposed subperiosteally. All levels were not instrumented- more screws were put on the concavity and in the periapical region. Facet release and costo-transverse release was carried out. The concave rod was first applied to the upper and lower screws and one of them was tightened fully, while in the other, the rod was captured but not fully tightened. This enabled the rod to slide as and when curve correction occurred. Then the convex rod was applied to the upper level of the construct and gradual capturing of the subsequent screws was done from the top to the bottom, thus providing axial translation of the spine. The rest of the anchor points on the concave side were then gradually captured with the apical ones being captured last. All the screws in the concave and the convex sides having been captured, they were fully tightened. Wake up test was done at this point to confirm that the patient is neurologically intact. Bone grafting from local bone iliac crest graft for fusion was performed. Wound was closed in layers after putting a closed suction drain. Depending on pain relief, the patient was mobilized with a brace by the third to the fifth day and discharged after suture removal on the tenth day. They usually were allowed to join school after one month and physical training was allowed after 3 months. Contact sports were allowed at least after 6 to 9 months.

\section{Results}

All the 20 patients were available for follow-up for minimum 18 months. Most of the cases were female i.e., $12(60.0 \%)$ and $8(40.0 \%)$ male patients. The mean age was 14.24 (age range: $10-24$ years). There were no cases of Lenke type 5 and type 6 were as majority of cases $60 \%$ were Lenke type 1 $20 \%$ were Lenke type 2 and $10 \% 3 \& 4$. The functional outcome, the mean SRS scores and correction percentage are shown in table II. The improvement was seen more in domains of self image and satisfaction. There was improvement in score from 3.38 to 4.13 at final follow-up which shows improvement from $67.6 \%$ to $82.6 \%$. An average improvement of $15 \%$ at final follow-up where $p<0.001$ using paired $t$-test and is statistically significant.

Radiographic outcome: The data were collected from the preoperative, immediate postoperative and the last follow-up x-rays.

The measurement show mean preoperative Cobb's angle of $21.55 \pm 6.64,53 \pm 5.89,33.05 \pm 7.68$ of proximal, main and lower thoracic region respectively (table I). There was significant improvement in cobb angle i.e., $32.31 \%$ in proximal thoracic, $62.06 \%$ in main thoracic and $50.65 \%$ in thoracolumbar region which showed correction was more on main thoracic curve and then in thoracolumbar/lumbar curves. Paired $t$-test showed significant result $(p<0.001)$ where correction was maintained until the last follow-up. 
Table I: Distribution of cases according to LENKE classification, age, sex and Cobb angle (Preoperative, Immediate Postoperative and final follow-up 18 months)

\begin{tabular}{|c|c|c|c|c|c|c|c|c|c|c|c|c|}
\hline Lenke & Cases & Age & Sex & $\begin{array}{c}\text { Pre-op } \\
\text { PT } \\
\end{array}$ & $\begin{array}{c}\text { Pre-op } \\
\text { MT }\end{array}$ & $\begin{array}{c}\text { Pre-op } \\
\text { TL/L }\end{array}$ & $\begin{array}{c}\text { Post-op } \\
\text { PT }\end{array}$ & $\begin{array}{c}\text { Post-op } \\
\text { MT }\end{array}$ & $\begin{array}{c}\text { Post-op } \\
\text { TL/L }\end{array}$ & $\begin{array}{c}\text { Final } \\
\text { F/u PT } \\
\end{array}$ & $\begin{array}{c}\text { Final } \\
\text { F/u MT }\end{array}$ & $\begin{array}{c}\text { Final } \\
\text { F/u TL/L }\end{array}$ \\
\hline Type 1 & 12 & 13.16 & M:4 ; F:8 & 22.58 & 51.33 & 30.58 & 13.67 & 20.75 & 15.16 & 14.25 & 21.67 & 15.91 \\
\hline Type 2 & 4 & 14.5 & $\mathrm{M}: 2 ; \mathrm{F}: 2$ & 23.75 & 52.75 & 37 & 14.75 & 18.25 & 14.75 & 15.5 & 19.5 & 15 \\
\hline Type 3 & 2 & 15 & $\mathrm{M}: 1 ; \mathrm{F}: 1$ & 15.5 & 59.5 & 36 & 13 & 20.5 & 19 & 16 & 21.5 & 19 \\
\hline Type 4 & 2 & 19.5 & $\mathrm{M}: 1 ; \mathrm{F}: 1$ & 17 & 57 & 37 & 14.5 & 20 & 18 & 18 & 21.5 & 18 \\
\hline
\end{tabular}

Table II: Functional outcome and correction percentage at different Lenke type curves

\begin{tabular}{cccc}
\hline Lenke & Cases & Pre-op SRS & Final F/u SRS \\
\hline Type 1 & 12 & 3.31 & 4.2 \\
Type 2 & 4 & 3.48 & 4.02 \\
Type 3 & 2 & 3.44 & 4.04 \\
Type 4 & 2 & 3.55 & 4.04 \\
Mean & 35 & 3.445 & 4.075 \\
\hline
\end{tabular}
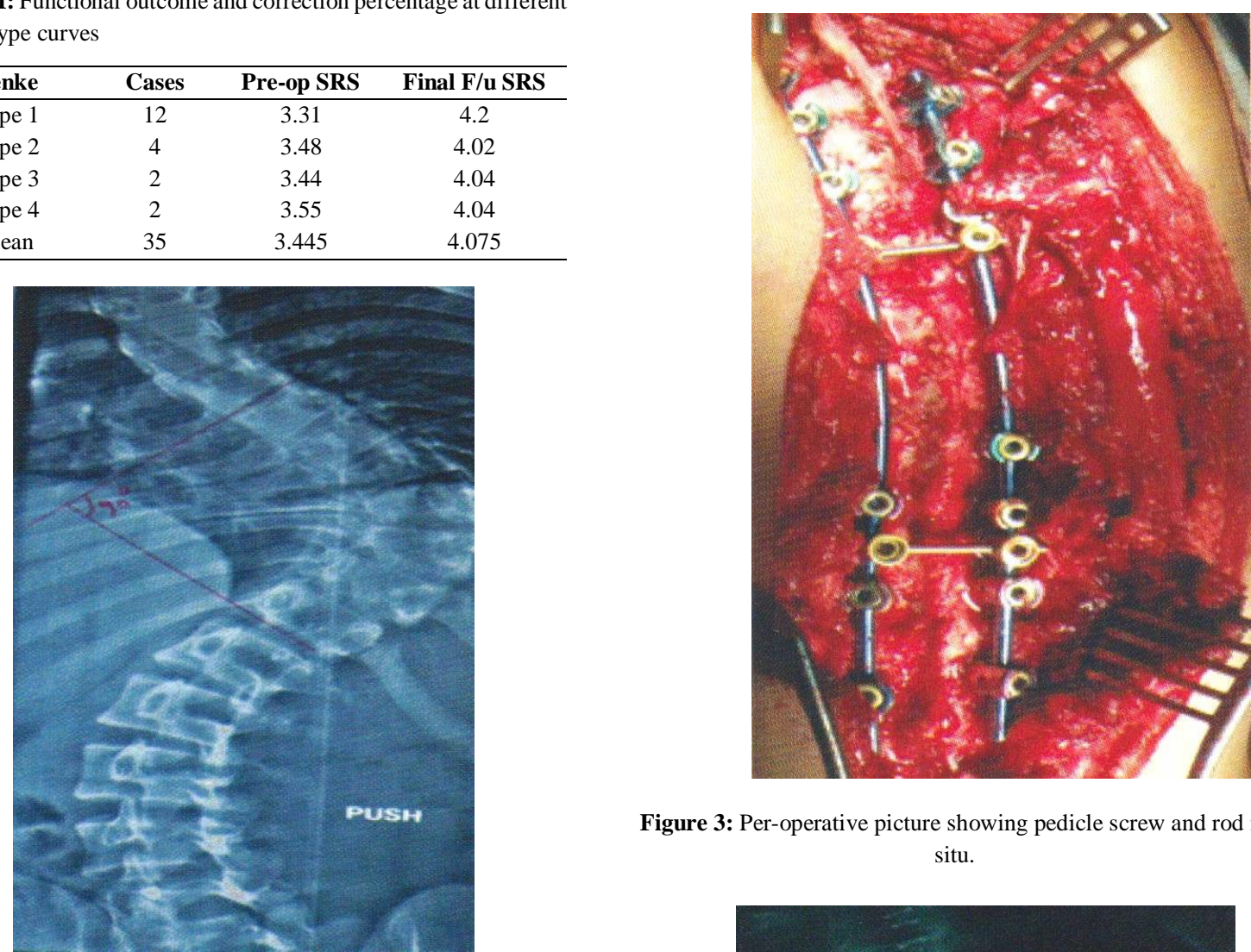

Figure 3: Per-operative picture showing pedicle screw and rod in situ.

Figure 1: Pre-operative $\mathrm{X}$-ray showing thoracic cobb angle is 90 degree.

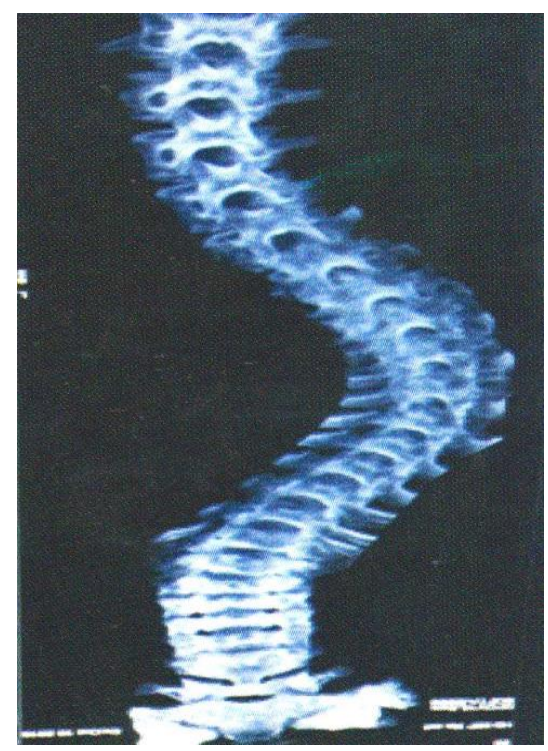

Figure 2: Pre-operative CT scan

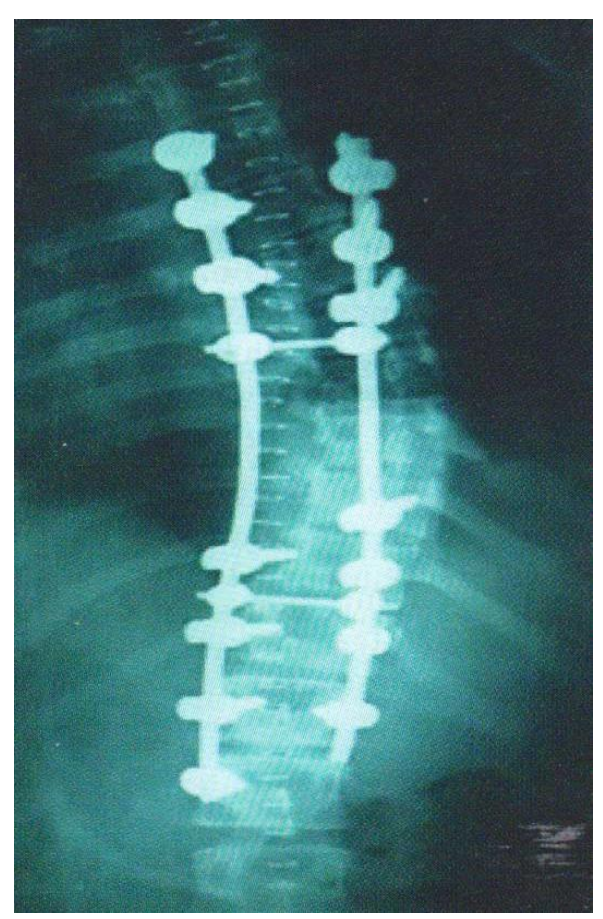

Figure 4: Postoperative X-ray showing Cobb Angle of 20 degree 


\section{Discussion}

The treatment of adult idiopathic scoliosis is revolutionizing by introduction of various techniques, each having advantage and disadvantage of their own, in this series universal system with axial translation technique was used. It was not used any hooks and pedicle screws were also not given in all levels. More screws were used in concavity and in the periapical region. The curve correction is nearly similar to those found by other authors. The similar construct and technique has also showed better results by Basu et al. ${ }^{10}$ Functional outcome was evaluated using SRS 30 outcome questionnaire which contains five domains- function, pain, self-image, mental health and satisfaction. It was to be found that significant improvement in satisfaction and self-image which was noted by SRS score. In the series of Lehmann and Lenke showed |SRS improvement about 7.1\% where as our series shows $15 \%$ improvement in SRS. ${ }^{4}$ In this study, it was able to achieve a correction of $32.31 \%$ in proximal thoracic curves, $62.06 \%$ in thoracic curves and $50.65 \%$ in thoracolumbar/lumbar curves which is similar to results shown by Benjamin et al where correction curve percentage is $35 \%, 62 \%, 41 \%$ of PT, MT and TL/L respectively. ${ }^{14}$ Islam showed Cobb angle correction from $58.25^{\circ}$ preoperatively to $23.35^{\circ}$ postoperatively in a study of 32 patients showing correction of $59.57 \% .{ }^{15}$ Crandall showed the final correction of translation group by $70 \%$ compared to derogation group by $47 \%$.

\section{Conclusion}

Axial translation technique with pedicle screws and rods construct through posterior approach is good option to achieve good clinical and radiological outcome for patients of Adolescent Idiopathic Scoliosis (AIS).

\section{Acknowledgement}

We are grateful to the Department of Orthopaedic Surgery, BSMMU and other several private hospitals in Dhaka for their co-operation in conduction of the study.

\section{References}

1. Harrington PR. Treatment of scoliosis: Correction and internal fixation by spine instrumentation. $\mathrm{J}$ Bone Joint Surg AM. 1962;44:591-610.
2. Luque ER. Segmental spinal instrumentation for correction of scoliosis. Clin Orthop Relat Res. 1982;192-198.

3. Cotrel Y, Dubousset J, Guillaumat M. New universal instrumentation in spinal surgery. Clin Orthop Relat Res. 1988;227:10-23.

4. Laxer E. A further development in spinal instrumentation. Technical Commission for Spinal Surgery of the ASIF. Eur Spine J. 1994;3:347-352.

5. Bernsterin P, Hentschel S, Platzek I, Huhne S, Ettrich $\mathrm{U}$ et al. Thoracal flat back is a risk factor for lumbar disc degeneration after scoliosis surgery. Spine J. 2014;14:925-932.

6. Lehman RA Jr, Lenke LG, Keeler KA, Kim YJ et al. Operative treatment of adolescent idiopathic scoliosis with posterior pedicle screw-only construct: Minimum three-year follow-up of one hundred fourteen cases. Spine (Phila Pa 1976). 2008;33:1598-604.

7. Kim YJ, Lenke LG, Kim J, Bridwell KH, Cho SK et al. Comparative analysis of pedicle screw versus hybrid instrumentation in posterior spinal fusion of adolescent idiopathic scoliosis. Spine (Phila Pa 1976) 2006;31:291-8.

8. Di Silvestre M, Bakaloudis G, Lolli F, Vommaro $\mathrm{F}$, Martikos $\mathrm{K}$ et al. Posterior fusion only for thoracic adolescent idiopathic scoliosis of more than $80^{\circ}$. Pedicle screws versus hybrid instrumentation. Eur Spine J. 2008;17:1336-49.

9. Lee SM, Suk SI, Chung ER. Direct vertebral rotation: A new technique of three dimensional deformity correction with segmental pedicle screw fixation in adolescent idiopathic scoliosis. Spine (Phila PA 1976) 2004;29:343-9.

10. Basu S, Rathinavelu S, Baid P. Posterior scoliosis correction for adolescent idiopathic scoliosis using side-opening pedicle screw-rod system utilizing the axial translation technique. Indian $\mathrm{J}$ Orthop. 2010;44:42-49.

11. Remes V, Helenius I, Schlenzka D, Yrjonen T, Ylikoski $\mathrm{M}$ et al. Cotrel-Dubousset (CD) or Universal Spine System (USS) instrumentation in adolescent idiopathic scoliosis (AIS) comparison of midterm clinical, functional and radiologic outcomes. Spine (Phila Pa 1976). 2004;29:202430 .

12. Cotrel Y, Dubousset J, Cuillaumat M. New universal instrumentation in spinal surgery. Clin Orthop Relat Res. 1988;227:10-23.

13. Laxer E. A further development in spinal instrumentation: Technical Commission for 
Spinal Surgery of the ASIF. Eur Spine J. 1944;3:347-52.

14. Benjamin K, Timothy R. K., Lawrence G. Lenke, Radiographic outcomes of anterior spinal fusion versus posterior spinal fusion with thoracic pedicle screws for treatment of Lenke Type I Adolescent Idiopathic Scoliosis curves. Spine 2005;1859-1866
15. Islam M A, Chaudhary R, Qamruzzaman P. An evaluation of correction of adolescent idiopathic scoliosis by pedicle screw and rod. Postgraduate Medical Journal of NAMS. 2018;18:18-22.

16. Dennis C, Revella J. Translation vs, derotational correction of adult scoliosis: a comparison of clinical and radiographic outcome. Spine J. 2009;10:177-178.

*Correspondence: Md. Anowarul Islam, Associate Professor, Department of Orthopaedic Surgery, Bangabandhu Sheikh Mujib Medical University, Dhaka, Bangladesh; e-mail: maislam.spine@gmail.com 